\title{
Improvement of Maritime Management as a Key Aspect of Sustainable Development and Blue Growth in the Russian Federation
}

\author{
Nikolay Plink ${ }^{1}$, Vera Semeoshenkova ${ }^{1}$, Tatyana Eremina ${ }^{1}{ }^{(0}$, Alexandra Ershova ${ }^{1, *}$ and Ivan Mushket ${ }^{2}$ \\ 1 Russian State Hydrometeorological University (RSHU), ul. Voronezhskaya, 79, \\ 192007 Saint-Petersburg, Russia; plink@rshu.ru (N.P.); vsemeoshenkova@gmail.com (V.S.); \\ tanya.er@gmail.com (T.E.) \\ 2 Interparliamentary Assembly of the Commonwealth of Independent States, ul. Stavropolskaya, 3, \\ 191015 Saint-Petersburg, Russia; imsk@mail.ru \\ * Correspondence: ershova@rshu.ru
}

Citation: Plink, N.; Semeoshenkova,

V.; Eremina, T.; Ershova, A.; Mushket,

I. Improvement of Maritime

Management as a Key Aspect of Sustainable Development and Blue Growth in the Russian Federation. J. Mar. Sci. Eng. 2021, 9, 1212. https:// doi.org/10.3390/jmse9111212

Academic Editor: Jin Wang

Received: 7 October 2021

Accepted: 24 October 2021

Published: 2 November 2021

Publisher's Note: MDPI stays neutral with regard to jurisdictional claims in published maps and institutional affiliations.

Copyright: (c) 2021 by the authors. Licensee MDPI, Basel, Switzerland. This article is an open access article distributed under the terms and conditions of the Creative Commons Attribution (CC BY) license (https:// creativecommons.org/licenses/by/ $4.0 /)$.

\begin{abstract}
The conservation and sustainable use of oceans, seas and marine resources has been declared by the United Nations as one of 17 priority Sustainable Development Goals. At present, most of the maritime states are striving to improve the efficiency of their use of marine resources, including sea space. In particular, the European Union is implementing a number of projects related to the implementation of marine spatial planning (MSP) tools. The Baltic Sea is considered as a pilot region, where a pan-Baltic coordinated MSP plan has been developed to provide for sustainable development and blue growth in the marine and coastal economy. The Russian Federation is one of the Baltic countries, but the MSP procedure at the state level does not have institutional and regulatory support, which requires the elimination of gaps and additional development of the maritime management system. The laws of the organization and development of the general theory of management are used in this study. An Integrated Management Model for sustainable marine and coastal use is proposed as a tool for ensuring blue growth, including four interrelated elements (specific management functions), namely "Integrated Coastal Zone Management", "Marine Spatial Planning", "Management of Marine Macroregion" and “Ocean Governance”. Their functional content and interaction mechanisms are discussed in order to implement an integral approach to marine use. The vertical structure of the proposed integral model includes three levels corresponding to the federal and regional levels of government and the level of municipal self-governance. The use of the integral model should help accelerate the process of introducing and using MSP instruments in the process of strategic planning in the socio-economic development of the Russian coastal territories.
\end{abstract}

Keywords: blue economy; maritime management; marine use; marine spatial planning; integrated coastal zone management

\section{Introduction}

The marine environment is the largest ecosystem in the world; it stabilizes the climate and supports life on Earth and human well-being. The development of the spaces and resources of the World Ocean along with the creation of improved conditions for sustainable development of the Ocean are among the main directions of the development of global civilization in the third Millennium [1,2]. However, ocean degradation with the attendant changes and losses in the structure, function and resulting benefits of marine systems has been observed. In this regard, adaptation strategies and science-informed policies responding to global change are urgently needed [1].

At present, there is tremendous goodwill in the global community when it comes to protecting the ocean [3]. The "Blue Economy" or "Oceans/Marine Economy" is an increasingly popular concept as a strategy for safeguarding the world's oceans and water 
resources, describing the conditions that may emerge when economic activity is in balance with the long-term capacity of ocean ecosystems to support such activity in a sustainable manner [4]. It has been heralded as a new approach to ocean governance, and refers to a broad set of policies aimed at supporting ocean-based economic activities that provide simultaneous improvements for economic, social, and environmental outcomes [5]. The notion of the blue economy has become more widely used since the United Nations Conference on Sustainable Development (UNCSD) in Rio de Janeiro in June 2012 [6,7]. The term "blue economy" is used for innovative ways of managing of marine resources. In a concept paper, the United Nations offered a general definition of the "Blue Economy" as an ocean economy that aims at "the improvement of human well-being and social equity, while significantly reducing environmental risks and ecological scarcities" [6]. Introduction of blue economy elements is a fundamentally important task in order to ensure the sustainable development of coastal countries. A wide range of tools can be used to solve this task, including the transition to alternative (renewable) energy sources, the introduction of resource-saving technologies, environmental education, public awareness and a number of other initiatives. A key factor for achievement of the sustainable use of the benefits of maritime activities is the introduction of a system of marine use that meets the level of modern challenges.

An adequate maritime management system should be based on the integrity of maritime activities, the hierarchy of specific management functions, the complexity of the development of coastal territories and coastal waters, the use of the ecosystem approach, and the possibility of active involvement for all subjects of maritime activities, including end users and the population of coastal territories, in the management of processes occurring on the sea and the adjacent land. Considering the vastness of the Russian sea areas and length of the coastline, the problem of integrated development of maritime activities is extremely relevant for the Russian Federation in the context of the need for balanced environmental and socio-economic development [8]. This paper aims to identify the role of maritime management and a need for implementing the integrated maritime management system in Russia by reviewing the experience of integrated approaches to maritime management both in the country and abroad, focusing on the Baltic Sea Region. Finally, an integrated maritime management model aimed at sustainable marine and coastal use is proposed and discussed.

Marine use can be defined as the sustainable use of mutually interacting marine and coastal areas and their resources, taking into consideration both public safety and the preservation of environmental quality. Thus, maritime management evidently includes:

- management of certain types of maritime activities (marine transport, fishing, offshore oil platforms, etc.);

- interaction with the economic sectors related to maritime activities (tourism and recreation, rail and road transport, etc.);

- ensuring the safety of coastal populations and managing the risks of natural marine disasters (typhoons, tsunamis, storm surges, etc.);

- environmental monitoring and environmental protection;

- management of other processes occurring at the junction of sea and land (coastal formation, preservation of marine cultural heritage, etc.).

Increasing attention has been focused on managing the multiple uses of marine space, especially in areas where conflicts among users and the environment are already clear. Moreover, a recent concern is associated with the need to conserve nature, especially ecologically and biologically sensitive areas, in the context of multi-use planning of ocean space [9]. The variety of marine and coastal resources, the presence of competing interests in their use, and the complex nature of the interaction of various natural and anthropogenic impacts make it rather difficult to develop an adequate maritime management system. The problem is compounded by the fact that in a number of coastal countries, including the Russian Federation, management has been historically based on a fragmented approach, which 
makes it difficult to solve comprehensive tasks such as blue growth and the sustainable development of maritime activities on the whole [10].

\section{An Integrated Approach to Maritime Management around the World}

The importance of strategic integration of multiple environmental, social and economic objectives and of a "holistic approach" to maritime management are often stressed in the related literature $[9,11]$. An integrated approach to management of maritime activities, together with the protection of marine environment, is used today in many countries throughout the world. Management models oriented on an integrated approach include the Integrated Coastal Zone Management (ICZM) model, which was developed in the early 1990s and later transformed into the Integrated Coastal Area Management (ICAM) model, or simply "Integrated Coastal Management "(ICM) [12,13]. Currently, a management model known as "Marine Spatial Planning" (MSP) is being actively developed globally, particularly in the Baltic Sea region [14-16]. Given the current level of interest in MSP and the political support it has in many regions of the world, the number of countries engaging with MSP is set to increase [17]. Integrated marine spatial plans have been implemented by about 20 countries, and it is expected that by 2030 at least a third of the surface area of the world's exclusive economic zones will have government approved marine spatial plans [18]. Management models focused on conservation of marine ecosystems implement an "ecosystem approach", defined by the Convention on Biodiversity as "a strategy for the integrated management of land, water and living resources that promotes conservation and sustainable use in an equitable way" [19]. Today, the ecosystem approach has become widely accepted as a key framework for supporting sustainable development in both the terrestrial and the coastal and marine environment. It provides an important framework for assessing biodiversity and ecosystem services and evaluating and implementing potential responses [20,21]. An example of the adaptation and use of traditional approaches in the management of natural resources in relation to marine objects is the so-called "basin approach"; in order to reduce the level of pollution of the sea, which as a rule is associated with the removal of pollutants with river runoff, the inclusion of the entire catchment area of rivers flowing into the sea within the management area is required. The catchment area of the Baltic Sea is about 1.7 million $\mathrm{km}^{2}$, which is more than four times larger than the area of the sea itself [22]. The sea is characterized by its weak water exchange with the open ocean; therefore, this approach finds its real reflection in the activities of Helsinki Commission (HELCOM) on the implementation of the Convention on the Protection of the Baltic Sea Environment.

This incomplete list of opportunities for using an integrated approach in maritime management reflects a wide range of models, each of which is aimed at solving a specific task related to marine or coastal activities: socio-economic development of coastal territories, harmonization of stakeholders' interests from various maritime sectors, preservation of marine ecosystems, mitigation of marine pollution, etc. At the same time. the exemplified models have overlapping goals and are based on similar basic principles, such as recognition of the wide scope of the problem, interdisciplinarity, consideration of different levels of management, the presence of interacting processes on land and the adjacent sea area, the use of environmental principles as criteria for making management decisions, and a number of other principles. Having common basic principles allows these models to be considered together.

Currently, the problem of combining the spatial planning of activities on land and at sea can be considered quite urgent due to the need to take coastal activities into account in the framework of marine spatial planning. Issues in Land and Sea interaction (LSI) [23] have been considered during the implementation of several Baltic projects (Land Sea Act, Pan Baltic Scope and BalticRIM), and the examples of world-wide good practices in this respect are presented in the EU MSP platform [24]. An MSP and LSI report prepared by the European Spatial Planning Observation Network (ESPON) and available at ESPON website [23] is a "one space" territorial planning approach, which was tested in five pilot 
marine areas (Slovenia, the Gulf of Gdansk, the Croatian coast and islands, the Dutch North Sea coast and the Pomeranian Bight) covering different LSI contexts and scales of analysis [25].

However, quite often the LSI process is viewed in the context of a sectoral approach, i.e., analysis of interactions within one or several different areas of maritime activity. The already mentioned pilot case-studies carried out within the framework of the Land Sea Act project of the Interreg Baltic Sea Region Programme (2019-2021) were focused on the development of the blue economy and were aimed at trade-offs and balanced use of land-sea resources, assessment of cultural values in "MSP and Blue Growth", taking into account climate change adaptation and sustainable tourism, as well as developing integrated coastal mobility and tourism planning, considering the problem of developing tourism entrepreneurships in small ports [25].

The solutions to the problems illustrated by the abovementioned pilot cases are united by the common idea of using the MSP tool to ensure Blue Growth and find trade-offs in vital coastal areas. However, even finding the most optimal spatial solution does not always guarantee final solutions to complex problems, which, as a rule, require consideration of a wider range of interrelated processes affecting the optimization or development of existing and new types of maritime activities.

Currently, the majority of maritime states strive to improve the efficiency of their use of marine resources, taking into account the conservation of the environment and biodiversity. At the same time, the sea space is considered as a certain resource that can be used, inter alia, in the interests of development of new types of maritime activities. At the same time, the use of the sea area can be of a conflicting nature. The European Union is implementing a number of projects related to the implementation of marine spatial planning tools. At the same time, special attention is being paid to the Baltic Sea, which is considered as a pilot region. An overall coordinated MSP plan is planned to be developed for sustainable development and blue growth of the marine and coastal economy in the Baltic Sea region. However, this raises the problem that part of the water area is under the jurisdiction of the Russian Federation, where the MSP procedure at the state level does not have institutional and regulatory support, which in principle hinders the achievement of the objectives in the field of MSP which are set at the European level. Therefore, the promotion of MSP methodology in the Russian Federation is an important and urgent task.

Improving the management of marine and coastal use is crucial for the Russian Federation in order to increase the efficiency of reaching the potential of maritime activities. The need to improve the management system, in general, is determined by the innovative development of coastal regions, diversification of maritime activities due to a more complete and efficient use of marine and coastal resources, and the need to develop preventive measures to ensure the preservation of the quality of marine coasts with intensification of maritime and coastal economic activities. The Strategy for the Development of Maritime Activities of the Russian Federation until 2030, approved by the order of the Government of the Russian Federation No. 1930-r dated 30 August 2019, determines "the need to supplement the existing predominantly sectoral approach to planning of maritime activities with an integrated approach" based on the combination of coastal territories and coastal waters within the framework of a single object of public administration [26]. The issues around delegation of a number of powers from the federal center to the regions are discussed in [27-29].

The national interests of the Russian Federation in the oceans are a set of balanced interests of the individuum, society and state in the area of maritime activities implemented through the law of the sea-building state. According to the Maritime Doctrine of the Russian Federation, the national interests of the Russian Federation in the oceans include protection of human life at sea, prevention of marine pollution, control of vital sea communications, creation of conditions conducive to the benefit of the maritime economic activities of the Russian Federation's population, especially in its coastal regions, as well as the state as a whole, etc. [2]. Considering the vastness of the sea areas of the Russian Federation and the 
length of the coastline, its coastal zones are distinguished by a significant difference in the level of socio-economic development and, as a result, have different tasks and prospects for their development [30]. At the same time, maritime activities here should have a management system integrating efforts in the field of marine transport, development of biological resources, development of marine mineral resources, and pursuing a unified policy in the field of conservation and protection of marine environment.

The harmonization of relations between various subjects of maritime and coastal activities and the active involvement of business representatives and the public in the process of its development both require a high level of horizontal integration. From the point of view of the management system, analysis of the process of horizontal integration should not be understood as merely a simple involvement of users of various marine and coastal resources in the process of managing maritime complex development. A horizontally integrated management system should include a set of specific functions that should ensure the possibility of a comprehensive solution to assigned tasks based on a wide scope of problems and finding optimal development paths that consider the interests of all participants in marine and coastal activities, including the environmental aspect. On the other hand, the goals and objectives of the marine national policy should be implemented in the form of specific projects embedded in the general plan, tied to a specific territory and thus requiring the involvement of local authorities. Thus, the management system of maritime activities should be multi-level, i.e., integrated not only horizontally, but also vertically.

To design a management model that meets the necessary areas of integration, the so-called matrix organizational structure was used, based on a combination of linear and functional management links [31]. Management links of the linear type harmonize the decision-making process at various levels of government (in the case of Russia, federal, regional and municipal), and links of the functional type enable the implementation of specific management functions within the framework of the general management model.

\section{Methodology and Results: An Integrated Management Model for Sustainable Marine and Coastal Use}

Ensuring sustainable blue growth is a national task and a great challenge for the Russian Federation, requiring the development and improvement of the maritime management system. The main vector of improvement of the maritime management system aimed at sustainable development of marine and coastal activities should be the transition from strategic planning to strategic management. In practice, in relation to the problems of marine use, this means a transition from the coordination of plans for the development of certain maritime sectors to the integration of the management models themselves within the framework where these plans have been developed [32,33]. As a matter of fact, separate management models aimed at fulfilling specific management functions should be combined within the framework of a more general integral model of sustainable maritime management. Models that implement specific management functions should interact with each other, giving the property of adaptability to the created integral model. This means that if MSP is considered as one of the specific management functions, then the adjustments made in the framework of the MSP process should be manifested not only in direct changes in the marine spatial plans, but also reflected in decisions made in the framework of other management models. In this sense, the proposed integrated model should be considered as a tool for the development and consistent implementation of coastal policy in general, considering the interaction of various stakeholder interests and existing challenges. It is clear that the implementation of such a model in practice is an extremely complex process that requires careful development and design. However, it seems appropriate to consider the possible general architecture of such an integrated model of marine use in relation to the problem of sustainable development of maritime and coastal activities (see Figure 1). 


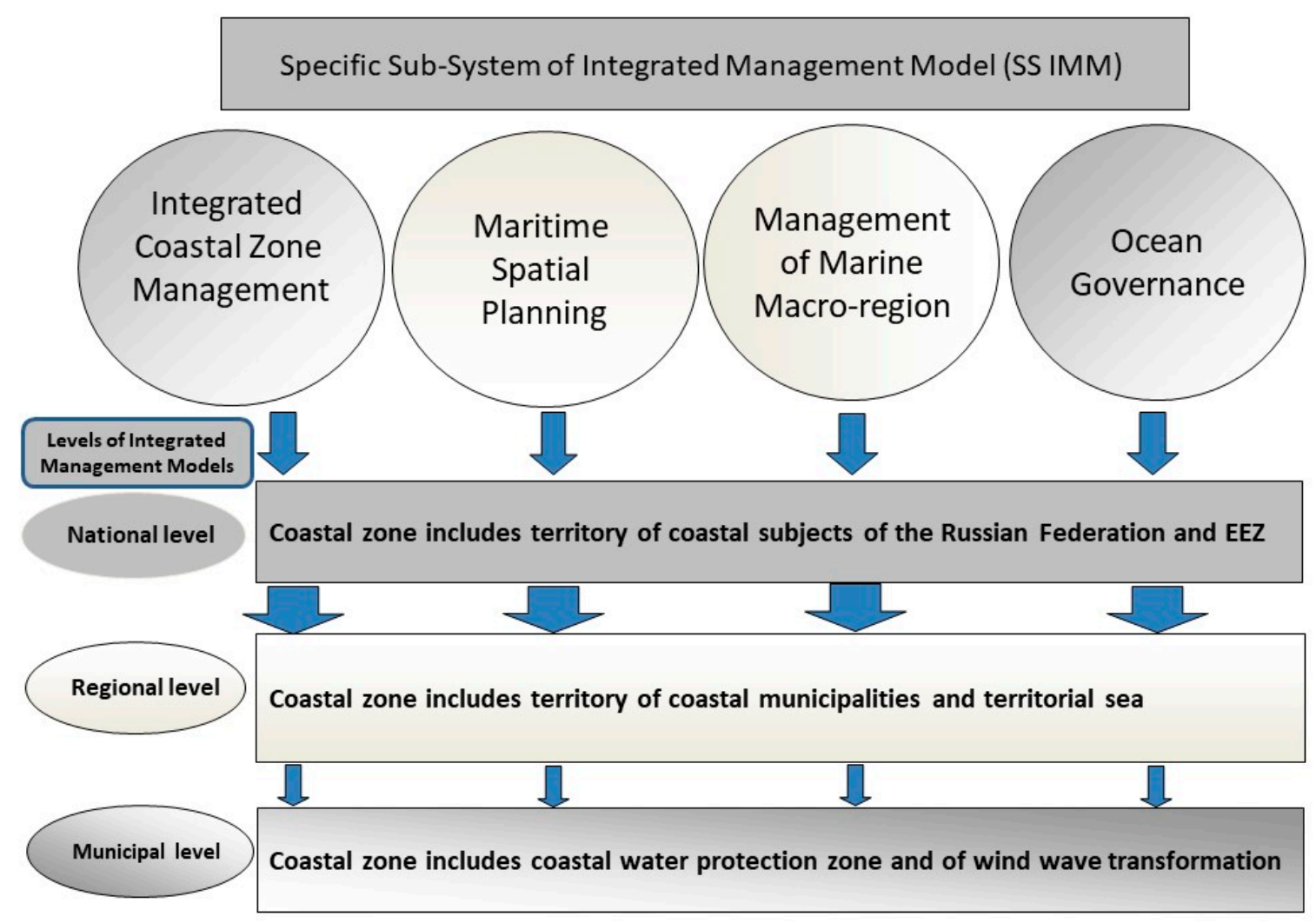

Figure 1. General structure of the proposed Integrated Management Model for sustainable sea and coastal use in the Russian Federation.

The considered integrated model of maritime management is based on the so-called matrix organizational structure. The linear part of the organizational structure includes three levels of management: the federal level, the regional (the level of the coastal subjects in the Russian Federation) and the local (municipal) level. Each level of management has its own spatial boundaries in terms of management objects, determined by the possibility of implementing real management functions.

The functional part of the integral model includes the implementation of four functions, which in our opinion are the main interrelated specific management functions (SMF), namely: integrated coastal zone management (ICM), marine spatial planning (MSP), management of marine macroregions, and ocean governance (see Figure 1). As already noted, models that implement the listed specific management functions are usually considered separately, creating the prerequisites for the emergence of fragmentation in management based on the use of separate management models. In this case, we will consider the possibility of their integration within the framework of a unified approach and consider their interaction. Obviously, each of the specific functions under consideration includes many procedures, the implementation of which will determine the effectiveness, quality and completeness of the implementation of the particular SMF. Without pretending to make a comprehensive analysis in this paper, we will focus only on the possible use of procedures that can promote blue growth and the sustainable development of maritime activities in the context of the Russian Federation.

\section{Subsystems of Integrated Management of Marine Use}

The functional parameters of subsystems of Integrated maritime management are presented at Figure 2. 


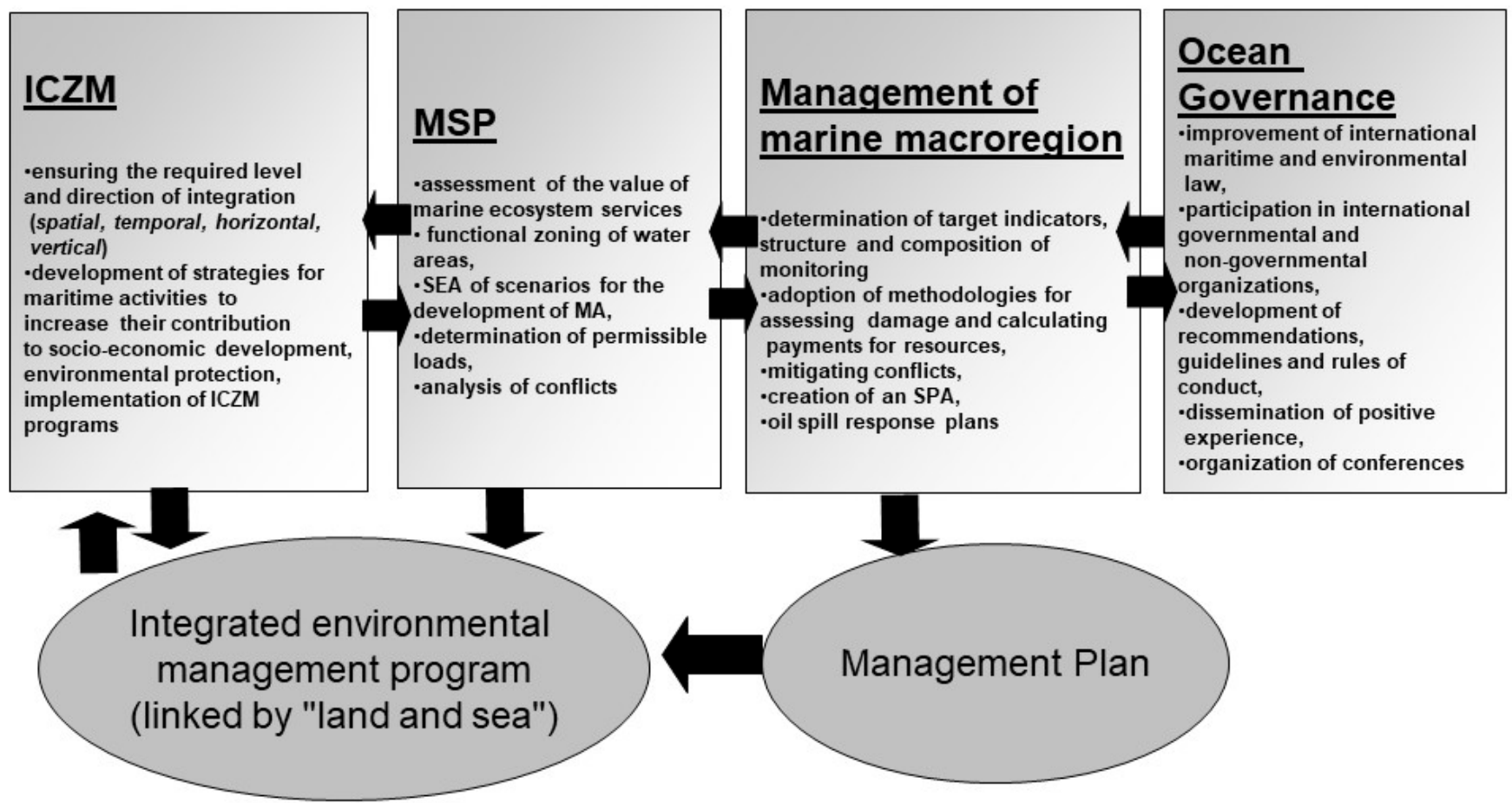

Figure 2. Functional parameters of subsystems of Integrated maritime management.

The main task of implementing the ICZM model is to create a system of vertical and horizontal links to be used in the future, in particular as a tool for involving stakeholders and the public in the process of managing the development of marine and coastal activities. At the federal level of the Russian Federation, a national system of goals and objectives for the development of maritime activities is determined. At the regional level, coastal and marine components of strategies for the socio-economic development of coastal regions in the Russian Federation are being developed in accordance with the Strategy for the Development of Maritime Activities until 2030, taking into account the integration of coastal territories and coastal waters within the framework of a single independent object of strategic planning [26]. As part of the preparation of the coastal and marine component, long-term and medium-term forecasts of maritime activities are developed on the basis of which regional tasks for the development of the marine economic complex are determined; the needs for the development of coastal infrastructure required for the implementation of plans for the development of maritime activities are assessed within the framework of territorial planning, then the tasks in the field of environmental protection are determined and proposals developed for the implementation of the necessary ICZM programs [34]. Methodological recommendations for the development of the coastal and marine component of strategies for the socio-economic development of the constituent entities of the Russian Federation were approved by the Ministry of Economic Development of the Russian Federation [35]. The list of ICZM programs may include proposals for the use of alternative energy sources (wind, wave, and tidal power), as well as programs to reduce energy and resource consumption in various fields of maritime activities, to create a production base for the appropriate equipment, implementation of technologies, etc. At the local level, taking into account the coastal and marine component, municipal programs for coastal zone development are adopted and specific projects are supported.

Within the framework of the MSP model the legal support of the marine spatial planning procedure is carried out as an independent task on the federal level of government. On the basis of regulations adopted with the participation of the regional level, functional zoning of the sea area is carried out with subsequent assessment of the value of marine natural ecosystems and the level of permissible loads. This is followed by a strategic environmental assessment (SEA) of the maritime activities plan developed within the 
framework of the ICZM model. The main task of the SEA procedure is to assess the change in the load on the ecosystem associated with the implementation of the plan of regional maritime development. An important task is to analyze the possibility of potential conflicts between marine users in the context of changes in the spatial or functional structure of the maritime economic complex. In addition, within the MSP framework useful proposals and recommendations can be developed for spatial solutions to existing or potential problems (the creation of protected areas, improving the procedure for environmental monitoring and other nature conservation measures, preserving the marine cultural and historical heritage, etc.). When developing the coastal and marine component, a spatial solution for the construction of wind power plants can be justified, taking into account their location both offshore and in the coastal zone. In our opinion, the inclusion of such proposals in the developing strategy of the coastal constituent entities of the Russian Federation (through the coastal and marine component) will contribute to the broad practical implementation of programs for the use of alternative energy sources based on the use of the full cycle principle: design, production, operation.

As a result of the joint interaction of the ICZM and MSP models, acceptable and "agreed" solutions on land and at sea are being developed which provide a basis for adopting a program of integrated environmental management in accordance with the Strategy for the Development of Maritime Activities until 2030. Taking into account the traditions and existing regulatory documents of strategic planning on the one hand, and the absence, at present, of a regulatory framework that defines the MSP procedure on the other, such a decision-making trajectory in the contemporary conditions of the Russian Federation seems to be the most optimal. In other words, at the initial step of MSP implementation the MSP procedure is proposed as part of the development of a regional program of integrated coastal and marine use that is regulated by already existing documents of the national strategic planning process [26,33]. When the experience of MSP tool implementation is accumulated, the legal basis of MSP itself can be developed as a set of self-sufficient (juridical and methodological) regulatory documents.

For Russia, a typical situation is the case when the coastal zone of the sea includes the territory of several constituent entities of the Russian Federation, the ICZM and MSP plans of which should also be interconnected. In this case, the water area of large marine water bodies with an adjacent coastal zone, which includes the territory of several constituent entities of the Russian Federation, can be considered as some kind of marine macroregion. Examples of such marine macroregions can be the enclosed seas of Russia (the White and Okhotsk seas), as well as the EEZs of the Arctic seas adjacent to the territory of Russia. In contrast to the ICZM and MSP models, the allocation of a marine macroregion as an object of management due to an increase in spatial coverage allows a more complete implementation of the ecosystem approach. In previous models, the ecosystem approach is also one of the fundamental principles; however, there it is limited to a relatively small spatial scale, which allows only partial control over impacts on marine ecosystems. With an increase in the spatial scale, it becomes possible to cover the ecosystem in a more comprehensive form and make coordinated management decisions for the entire sea.

When implementing the management model for a Marine Macroregion, the specific procedures are determining the structure and composition of environmental monitoring, adopting a system of ecosystem indicators, adopting methods for damage assessment, calculating payments, and developing plans for mitigation of the consequences of natural disasters and industrial accidents. The final result of the implementation of the marine macroregion management model is the development and formal adoption of an Action Plan for macroregion management. The Action Plan is developed through successive interactions: contradictions (or new opportunities) are revealed during analysis of the interaction of the coastal regions of the Russian Federation that are part of the marine macroregion; as a next step, management measures are developed for their harmonization. Appropriate adaptation within the framework of the MSP and ICZM models is considered, analyzed and again synthesized within the framework of a more general management 
model of the marine macroregion. As a result of this iterative process, the necessary changes are made (or not) to the Management Plan.

The Ocean Governance model can be viewed as a version of democratic governance of global ocean development by countries, regional and local communities, industry, business, non-governmental organizations and other stakeholders. It is focused on harmonizing the interests and positions of all actors at all levels of decision-making in order to achieve the goals of civil society in individual countries and the world as a whole. Specific management functions of the ocean governance model include the improvement of maritime and environmental international law, participation in international governmental and non-governmental organizations, development of recommendations, guidelines and rules of conduct, dissemination of good practices, and organization of major conferences. The model can be used not only to implement the co-governance function in the open sea, but also in the context of transboundary cooperation to solve common problems, for example, to harmonize the MSP process in the Baltic Sea States.

\section{Discussion}

Obviously, this article sets out only the most general principles for constructing an integral model of maritime management in Russia. The result of the study is the structure of the proposed integral management model, which can be tested in real conditions only after its official approval by the government and in the legal field of the Russian Federation. In general, it is suggested on the basis of available world experience to select a number of already existing models that have already been tested to one degree or another and have some experience of practical implementation, then combine them within the framework of a general integral model of maritime management. The main problem with using such an integral model is the creation of mechanisms of interaction between individual functional models, since at present the use of these models is rather isolated, in our opinion, and in some cases they are even opposed to each other. Therefore, this article discusses the possibility of integrating the selected four management models that most meet the objectives of sustainable development of maritime activities and provide a general algorithm for establishing such interaction in relation to the conditions of the national maritime policy of Russia. However, in our opinion, such an approach to the design of a system of sustainable maritime management based on the composition and decomposition of a set of management functions in the field of marine use has a number of advantages:

- The model does not require a complete finalization of its structure, but can be "built up" gradually and in any sequence;

- The possibility of implementing all management functions (except for the MSP) in the Russian Federation has already seen some progress; therefore, the integrated maritime management model will not need to be created completely from scratch, but can be formed from existing elements;

- The presence of a certain degree of backlog can reduce the time and costs of transitioning the maritime management system to the use of a more current integral model;

- The introduction of the integral model does not require the formation of a new governing body; rather, improvement of ocean governance is implemented through the redistribution of existing management functions.

The organizational design of the maritime management system in the form of the integral model makes it possible to improve the management system by strengthening its innovative component. Considering an integrated and systematic approach to maritime use, the management concept should be based on logistical principles aimed at management so as to achieve the maximum positive effect for the entire system as a whole, and not merely for its individual subsystems. The idea of a logistic approach to managing complex systems and its differences from traditional management can be illustrated by the following example: let there be some system $S$ that requires management of the processes inside; in our specific case, it is a system of marine use, the management of which is realized through the implementation of four specific management functions. These in turn can be 
considered as links of a more general logistic system $\left(\mathrm{N}_{1}, \mathrm{~N}_{2}, \mathrm{~N}_{3}, \mathrm{~N}_{4}\right)$ interacting with each other by developed material, information and financial flows. In the general case, specific management functions not only have different functional content, but also relate to different parts of the coastal and marine zone. The ICZM model is confined to the coastal zone, and the Ocean Governance model, on the contrary, to the open sea. Therefore, the implementation of specific management functions can be considered as the management of various interconnected links in the general marine use system.

Let the target management function $\mathrm{F}_{\mathrm{S}}$ be aimed at increasing the contribution of maritime activities to the socio-economic development of coastal areas, i.e., the management task is to maximize the function. Within the framework of traditional management, this problem is solved in the following form:

$$
\left(\operatorname{Max} F_{s}\right)=\operatorname{Max} F\left(N_{1}\right)+\operatorname{Max} F\left(N_{2}\right)+\operatorname{Max} F\left(N_{3}\right)+\operatorname{Max} F\left(N_{4}\right),
$$

This scheme assumes that maximum efficiency using system $S$ is achieved by each link attaining its maximum efficiency of via mobilization of its internal resources. Coordination in the management of individual links within this approach may even be absent. A classic example of such an approach to management is a sectoral approach to maritime activities that is typical for many maritime states in the world, and Russia in particular. At the same time, it is a priori assumed that the better the functioning of various maritime sectors, the greater the contribution of maritime activity to overall development. In principle this is true, but this path does not always turn out to be the most effective and innovative. The disadvantages of this approach to management include the danger of duplicate functions and the intensification of conflict over internal resources. In addition, there is the risk of so-called sub-optimization, where the level of optimization of individual links in the overall system becomes unbalanced. In this case, over-optimization of one or more subsystems above the required level can lead not to an increase in the efficiency of the entire system, but rather to its decrease. For example, excessive attention to the MSP subsystem (management of processes in the coastal zone) and underdevelopment of the ICZM subsystem tools (determining the interactions with coastal processes) can lead to an unbalanced development of maritime activities and coastal infrastructure, which will reduce the overall efficiency the maritime complex. Overestimated environmental requirements can lead to a slowdown in the development of the blue economy, which can also be interpreted as lost benefits and a decrease in the efficiency of the use of marine resources. Therefore, such a management principle can only be successful for relatively simple management systems with weak feedbacks between various links.

In the case of the proposed logistic approach to management this task is transformed as follows:

$$
\left(\operatorname{Max} F_{S}\right)=\operatorname{Max}\left[F\left(N_{1}\right)+F\left(N_{2}\right)+F\left(N_{3}\right)+F\left(N_{4}\right)\right]
$$

In this case, maximum efficiency is achieved by influencing the entire system, taking into account the interconnections of its individual links. The fundamental difference from the previous case is that the final effect of management is assessed from the standpoint of the interests of the entire system as a whole, and not of its individual links. In this case, an option is possible when the maximum efficiency of the system will be achieved while reducing the costs of implementing specific management functions by achieving a synergistic effect. At the same time, the risk of conflict situations in the process of marine use is reduced, while increasing the possibilities for forecasting. This approach to maritime management is, in our opinion, preferable; however, it requires the construction of a general integral model, the substantiation of which is the task of this article. As already mentioned, the introduction of integral management methods in the Russian Federation is at an early stage; therefore the proposed model should be considered as the first step towards building a model that determines its overall content, architecture and the subject area of its constituent subsystems. Further steps to form an integral model of maritime use 
should be the development of the functional content of specific management functions and institutional transformations aimed at its practical implementation.

The integral model of maritime management proposed within the framework of this study was tested while comparing the positive international experience obtained through analysis of the related literature, discussions with the expert community, participation in round tables and thematic conferences with stakeholders, as well as personal participation in international and national projects on this topic, in particular the INTERREG program Capacity4MSP platform project "Strengthening the capacity of MSP stakeholders and decision-makers". In order to achieve the regional features and support the geographically wide discussion of the opportunities for application of the integral approach to marine use, a series of round tables with the participation of representatives of government, business, and public environmental organizations were held in various coastal regions: the Baltic Sea (Eastern part of the Gulf of Finland, Kaliningrad Oblast- the city of Kaliningrad), the Arctic zone of the Russian Federation (the city of Murmansk), the Far East (the city of Vladivostok), and the Caspian Sea (the city of Astrakhan'), as well as Moscow.

Another fact that testifies in favor of the proposed model is that all of the specific management functions included in the model are in demand and, to one degree or another, have already been introduced into the practice of marine use $[8,26,27,29]$. Some elements of the integral model, for example those related to the MSP subsystem, are still at the level of discussion of the Roadmap and the development of measures for the implementation of the MSP tools in practice in the Russian Federation. A clear understanding of the interaction tools for various subsystems will facilitate their integration within a single common management model. In terms of management theory, the introduction of an integral model means the transition of the maritime management system from strategic planning to strategic management.

Introduction of the MSP approach is one of the key issues and gaps in the transition to the integral model today. The main barriers to the implementation of the MSP procedure in Russia have been discussed in the frame of implementation of the Capacity4MSP Interreg Baltic Sea Region project $[32,36,37]$. An important guarantee is the adaptation of the best practices for the implementation of MSP, for example, developed for the Baltic Sea region, and the maintenance of transboundary cooperation $[20,32,38]$. The earliest elimination of barriers to the introduction of MSP will accelerate the transition to an integrated maritime management model and give a finished look to its structure. An integral model can become an effective tool for sustainable development of the coastal-marine economy and maritime activities in Russia in general, as well as for harmonization of the interests of stakeholders, introduction of energy and resource-saving technologies, and other elements of the blue economy.

One of the directions of blue growth is the transition to renewable energy sources, including those related to maritime activities. The European experience in the construction of wind power plants in offshore areas can be used in the Russian Federation. The energy of wind, waves and tides can be used as other marine energy sources. However, in all cases, the rational placement of large technological objects such as power generating polygons will require the development of methods of spatial planning and strategic assessment of the environmental impacts.

The purpose of introducing an integrated maritime management model is to obtain a synergistic effect aimed at achieving sustainable development goals and blue growth, increasing the contribution of maritime activities to the socio-economic development of coastal regions by improving the management system, harmonizing the interests of both state and business, finding optimal solutions in development of maritime activities, and increasing the efficiency of the use of marine and coastal areas.

\section{Conclusions}

As the general theory of management states, each management system seeks to tune in to the most optimal type of functioning. Changes in the external environment and the 
emergence of new strategic goals and objectives lead to the need to update the management system by improving a set of specific management functions in terms of their structure and content. This process is ongoing and is an objective reality. However, if the process of tuning the management system is spontaneous, without proper analysis of the new needs and problems arising in the management system in connection with new challenges, and proceeds in "trial and error" mode, such a process of "self-tuning" usually leads to unreasonable expenditures and delays in the modernization of management systems. As a result, a situation may arise where, in a rapidly changing external environment, the optimal structure of the management system aimed at the best and most cost-effective result is not achieved. In this case, energy will mainly be directed not at fast and effective movement towards solving the new problems, but at solving the contradictions that arise in the process of implementing managerial decisions, the emergence of new gaps, and the ineffectiveness of the resulting solutions. Such a strategy of "patching holes" does not allow for the achievement of positive synergy and confident movement towards obtaining the required positive results.

The presented integral maritime management model is focused on the formation of a common vision of the development of a maritime management system, aimed at ensuring the possibility of sustainable maritime activities, rational use of marine and coastal resources, implementation of an approach to the ecosystem, and the development of other maritime sectors which are inextricably linked with the transition to the blue economy. The formulation of a general management concept, in our opinion, will facilitate the implementation of specific management functions, in particular a marine spatial planning tool, which is especially important for the Russian Federation at the present time. It should be recognized that key government bodies in the fields of marine resources use and environmental protection, as well as marine stakeholders have some doubts about the need for MSP as a strategic planning tool, although the tasks of sustainable development and the transition to blue growth and the rational use of marine areas, including offshore areas, are national priorities of the Russian Federation. Understanding the prospects of the development of the general structure of the maritime management system will increase general interest in the transition from fragmentary management of maritime activities to the introduction of an integrated approach.

Author Contributions: Conceptualization, N.P. and I.M.; methodology, N.P. and V.S.; investigation, N.P., V.S., T.E. and A.E.; writing—original draft preparation, N.P., V.S., T.E. and A.E.; writing-review and editing, N.P., V.S., T.E. and A.E.; visualization, V.S. and A.E.; supervision, I.M.; project administration, T.E. and A.E. All authors have read and agreed to the published version of the manuscript.

Funding: This research was supported by INTERREG program Capacity4MSP platform project "Strengthening the capacity of MSP stakeholders and decision-makers".

Institutional Review Board Statement: Not applicable.

Informed Consent Statement: Not applicable.

Acknowledgments: For this article, the materials and results of the discussion of the round tables held within the framework of the CAPACITY4MSP project were used, providing the basis for discussing the need to improve the maritime management system in Russia.

Conflicts of Interest: The authors declare no conflict of interest.

\section{References}

1. UN. The United Nations Decade of Ocean Science for Sustainable Development (2021-2030), IOC Brochure 2020-4 (IOC/BRO/2020/4); 2021; 18p. Available online: http://plymsea.ac.uk/id/eprint/9441/ (accessed on 23 October 2021).

2. Maritime Doctrine of Russian Federation 2020. Approved by the President of the Russian Federation on 26 July 2015. Available online: https://d1wqtxts1xzle7.cloudfront.net/45530348/Russian_Maritime_Policy_2020-with-coverpage-v2.pdf? Expires=1635767377\&Signature=FRvzYy53Cv8uQvHJJSiJ8IDOZUIDhJZxXTpiGxRUAzih5kkpGHfEt2suUi4 3GxRUGdDB1o8xV8jsR484EiPi3c0SCHE0YY1fWUaSujmYQj6CpFfTVT3-zNuR5GMxKPh1AHaVBSswvME-mby9SSAKMi\{\}AmNg8vkElJzxEVHUlhlaypnb1WpMtUSxMkfFL \{\}JJ7BLp3lUgbOcxkQX08LU0yzpzZfdOFaPqdE4pMEDBtrJ0kmr0 
6d9FTI4j7ls0w YpNsfgNnnUQdoNnho6cp1C-Xn2NVzxeSyraTpvwtePww5WQdjNsb1N \{\}x2Q5vGX33VqCUZdTbRKn3 SbCEAfCOCCqXA_\&Key-Pair-Id=APKAJLOHF5GGSLRBV4ZA (accessed on 23 October 2021).

3. Ryabinin, V.; Barbière, J.; Haugan, P.; Kullenberg, G.; Smith, N.; McLean, C.; Troisi, A.; Fischer, A.; Aricò, S.; Aarup, T.; et al. The UN Decade of Ocean Science for Sustainable Development. Front. Mar. Sci. 2019, 6, 10. [CrossRef]

4. Silver, J.J.; Gray, N.J.; Campbell, L.M.; Fairbanks, L.; Gruby, R.L. Blue Economy and Competing Discourses in International Oceans Governance. J. Environ. Dev. 2015, 24, 135-160. [CrossRef]

5. Lee, K.-H.; Noh, J.; Khim, J.S. The Blue Economy and the United Nations' sustainable development goals: Challenges and opportunities. Environ. Int. 2020, 137, 105528. [CrossRef] [PubMed]

6. UNCTAD. United Nations Conference on Trade and Development, the Ocean Economy: Opportunities and Challenges for Small Island Developing States. 2014. Available online: http:/ / unctad.org/en/publicationslibrary/ditcted2014d5_en.pdf (accessed on 7 September 2021).

7. EPRS. The Blue Economy. Overview and EU Policy Framework. In-Depth Analysis. 2020. Available online: https://www europarl.europa.eu/RegData/etudes/IDAN/2020/646152/EPRS_IDA(2020)646152_EN.pdf (accessed on 7 September 2021).

8. Kachur, A.N.; Mikhailichenko, Y.G.; Maslennikov, S.I.; Sereda, A.V. Experience and prospects of integrated management of marine natural resources in the Far East of Russia. In Bulletin of the Far East Branch of the Russian Academy of Sciences, No. 1; 2019; pp. 75-89. Available online: https:/ / www.prlib.ru/en/node/ 686906 (accessed on 23 October 2021).

9. Lieberknecht, L.M. Ecosystem-Based Integrated Ocean Management: A Framework for Sustainable Ocean Economy Development; A report for WWF-Norway by GRID-Arendal; 2020. Available online: https:/ / www.grida.no/publications/477 (accessed on 23 October 2021).

10. Mikhailichenko, Y.G. Adaptation and Development of World Experience in Integrated Management of Coastal Zones of the Seas//Izv. RAS; Geography series 2004. No. 6; 2004; pp. 31-40. Available online: http://www.coastalwiki.org/wiki/Integrated_Coastal_Zone_ Management_(ICZM) (accessed on 23 October 2021).

11. GEF LME: LEARN. Large marine Ecosystems. In Marine Spatial Planning Toolkit; GEF LME: LEARN: Paris, France, 2018; Available online: https: / /ioc.unesco.org/topics/large-marine-ecosystems (accessed on 23 October 2021).

12. Kay, R.; Alder, J. Coastal Planning and Management; E\&FN Spon, Routledge: London, UK, 1999; 371p.

13. UNEP/MAP/PAP: Guidelines for the Preparation of National CZM Strategies Required by the Integrated Coastal Zone Management (ICZM); Protocol for the Mediterranean. Split, Priority Actions Programme; 2015. Available online: https://www.google.com.hk/search?q= Guidelines+for+the+Preparation+of+National+CZM+Strategies+Required+by+the+Integrated+Coastal+Zone+Management+\&ei $=$ D5qAYbjCNInL-Qak1LfIBw\&oq=Guidelines+for+the+Preparation+of+National+CZM+Strategies+Required+by+the+Integrated+ Coastal+Zone+Management+\&gs_lcp=Cgdnd3Mtd216EAMyCQgAELADEAcQHjIJCAAQsAMQBxAeMgkIABCwAxAHEB4 yCQgAELADEAcQHjIJCAAQsAMQBxAeMgkIABCwAxAHEB4yCQgAELADEAcQHjIJCAAQsAMQBxAeMgkIABCwAxAHEB4 yCAgAEIAEELADSgQIQRgBUJwIWJwIYIkNaAFwAHgAgAEAiAEAkgEAmAEAoAECoAEByAEKwAEB\&sclient=gws-wiz\& ved=0ahUKEwj4hbL2yPjzAhWJZd4KHSTqDXkQ4dUDCA0\&uact=5 (accessed on 23 October 2021).

14. Ehler, C.N. A Global Review of Marine Spatial Planning; Ocean Visions Consulting: Paris, France, 2012; 133p.

15. Maritime Spatial Planning. Past, Present, Future. In Palgrave MacMillan; Zauca, J., Gee, K., Eds.; 2019; ISBN 978-3-319-98696-8. (eBook). Available online: https://ec.europa.eu/oceans-and-fisheries/ocean/blue-economy/maritime-spatial-planning_en (accessed on 23 October 2021).

16. Palmowski, T.; Tarkowski, M. Baltic Cooperation in Marine Spatial Planning. Balt. Reg. 2018, 10, 100-113. [CrossRef]

17. Ehler, C. World-Wide Status and Trends of Maritime/Marine Spatial Planning. In Proceedings of the 2nd International Conference on Marine/Maritime Spatial Planning, Paris, France, 15-17 March 2017; UNESCO: Paris, France, 2017. Available online: https: / / www.iwlearn.net/documents/28618 (accessed on 23 October 2021).

18. Ehler, C.; Zaucha, J.; Gee, K. Maritime/Marine Spatial Planning at the Interface of Research and Practice. In Maritime Spatial Planning; 2019; 21p, Available online: https:/ /link.springer.com/chapter/10.1007/978-3-319-98696-8_1 (accessed on 23 October 2021). [CrossRef]

19. Convention on Biodiversity. Available online: https://www.cbd.int/convention/text/ (accessed on 1 October 2021).

20. Douvere, F. The importance of marine spatial planning in advancing ecosystem-based sea use management. Mar. Policy 2008, 32, 762-771. [CrossRef]

21. Douvere, F.; Ehler, C. New perspectives on sea use management: Initial findings from European experience with marine spatial planning. J. Environ. Manag. 2009, 90, 77-88. [CrossRef] [PubMed]

22. HELCOM Third Periodic Assessment of the State of the Marine Environment of the Baltic Sea, 1989-1993; Executive Summary Baltic Sea Environment Proceedings (BSEP) N 64 A, B; 1996. Available online: http://archive.iwlearn.net/helcom.fi/publications/bsep/ en_GB/bseplist/index.html (accessed on 23 October 2021).

23. ESPON. Policy Brief//Maritime spatial planning and land-sea interactions. In MSP-Maritime Spatial Planning and Land-Sea Interactions; Targeted Analysis; Version 20/02/20. Final Report; 2020; 69p. Available online: https://www.espon.eu/MSP-LSI (accessed on 8 July 2021).

24. European MSP Platform. 2021. Available online: https://www.msp-platform.eu/ (accessed on 8 July 2021).

25. Land-Sea-Act. Interreg Baltic Sea Region. Project \#R098 Land-Sea Interactions Advancing Blue Growth in Baltic Sea Coastal Areas. All Activities. Available online: https:/ /land-sea.eu/all-activities/ (accessed on 8 July 2021). 
26. Strategy for the Development of Maritime Activities of the Russian Federation until 2030. Approved by the Order of the Government of the Russian Federation No 1930-r dated 30 August 2019. Available online: https://digital-commons.usnwc.edu/ rmsi_research/6/ (accessed on 23 October 2021).

27. Denisov, V.V.; Mikhailichenko, Y.G. Current problems of marine management (example of the Barents Sea). J. Reg. Ecol. 2017, 3, 5-16. (In Russian)

28. Denisov, V.V.; Mikhailichenko, Y.G. On the role of regional authorities in the management of the coastal sea areas of Russia//Strategic planning in regions and cities of Russia: Building a system. In Reports of the Participants of the XII All-Russian Forum of Strategic Planning Leaders; Issue No. 16. St. Petersburg. 21-23 October 2013; Zhikharevich. SPb., B.S., Ed.; Leontief Center: St. Petersburg, Russia, 2014; pp. 90-92. Available online: https:/ / forumstrategov.ru/?lang=eng (accessed on 23 October 2021). (In Russian)

29. Denisov, V.V.; Mikhaylichenko, Y.G. Management of the Russian Arctic Seas//Best Practices in Ecosystem based Oceans Management in the Arctic; Report Series; Håkon, H., Ed.; Norwegian Polar Inst.: Tromsø, Norway, 2009; pp. 19-35.

30. Mikhaylichenko, Y.G.; Sinetsky, V.P. The Marine Policy of the Russian Federation: Its Formation and Realization. In Routledge Handbook of National and Regional Ocean Policies, 1st ed.; Routledge: London, UK, 2015; 24p, ISBN 9781315765648. Available online: https: / www.taylorfrancis.com/chapters/edit/10.4324/9781315765648-16/marine-policy-russian-federation-formationrealization-yuriy-mikhaylichenko-valentin-sinetsk (accessed on 23 October 2021).

31. Smirnov, E.A. "Fundamentals of the Theory of Organization": Textbook for Universities; UNITI; 2000; 375p, (In Russian). Available online: https:/ / smallbusiness.chron.com/principles-organizational-theory-75374.html (accessed on 23 October 2021).

32. Plink, N.L.; Kuznetsova, M.N. Models of integrated maritime management. In Proceedings of the III All-Russian Conference "Hydrometeorology and Ecology: Achievements and Development Prospects"; 2019. SPb.: KHIMIZDAT. Available online: https: / / www.google.com.hk/search?q=Hydrometeorology+and+Ecology $\% 3 A+$ Achievements+and+Development+Prospects\&ei= yZuAYbSYDZeRoAS5hrqoBg\&oq=Hydrometeorology+and+Ecology\%3A+Achievements+and+Development+Prospects\& gs_lcp=Cgdnd3Mtd216EANKBAhBGAFQzRBYzRBgjRdoAXAAeACAAbMBiAGzAZIBAzAuMZgBAKABAqABAcABAQ\& sclient=gws- wiz\&ved=0ahUKEwj0oOzIyvjzAhWXCIgKHTmDDmUQ4dUDCA0\&uact=5 (accessed on 23 October 2021).

33. Plink, N.L. Place of Maritime Spatial Planning in integrated system of sea management "Modern problems of hydrometeorology and environmental monitoring in the CIS". In Proceedings of the International Scientific and Practical Conference Dedicated to the 90th Anniversary of the Russian State Hydrometeorological University, St. Petersburg, Russia, 22-24 October 2020; Russian State Hydrometeorological University: St. Petersburg, Russia, 2020; pp. 79-80.

34. Plink, N.L. On the development and implementation of integrated coastal zone management programs. Strategic planning in the regions and cities of Russia: Updating strategies, updating meanings. In Proceedings of the XIII All-Russian Forum of Strategic Planning Leaders/Ed; Zhikharevich, B.S., Ed.; ICSEI Leontief Center: St. Petersburg, Russia, 2015; pp. 70-72. Available online: https:/ / xueshu.baidu.com/usercenter/paper/show?paperid=171v0vm0986t0m50910a0400d5792309 (accessed on 23 October 2021).

35. Methodological Recommendations for the Development and Adjustment of the Socio-Economic Development of the Constituent Entity of the Russian Federation and an Action Plan for its Implementation, Approved by Order of the Ministry of Economic Development of Russia, 23 March 2017. Available online: https://www.google.com.hk/search?q= 35.\%09Methodological+recommendations+for+the+development+and+adjustment+of+the+socio-economic+development+ of +the+constit-uent+entity+of+the+Russian+Federation+and+an+action+plan+for+its+implementation $\% 2 \mathrm{C}+$ approved + by + order+of+the+Ministry+of+Eco-nomic+Development+of+Russia\&ei=cZyAYcDXBsz7wAPk3ra4Ag\&oq=35.\%09Methodological+ recommendations+for+the+development+and+adjustment+of+the+socio-economic+development+of+the+constit-uent+entity+ of +the+Russian+Federation+and+an+action+plan+for+its+implementation $\% 2 \mathrm{C}+$ approved+by+order+of +the+Ministry+of + Eco-nomic+Development+of+Russia\&gs_lcp=Cgdnd3Mtd216EAMyEQgAEOoCELQCEIoDELcDEOUCMhEIABDqAhC0 AhCKAxC3AxDlAkoECEEYAFDhCFjhCGDxDmgBcAB4AIABAIgBAJIBAJgBAKABAaABArABAsABAQ\&sclient=gws-wiz\& ved=0ahUKEwiA1POYy_jzAhXMPXAKHWSvDScQ4dUDCA0\&uact=5 (accessed on 23 October 2021).

36. Semeoshenkova, V.S.; Plink, N.L.; Eremina, T.R.; Ershova, A.A.; Mushket, I.I. Barriers to the Implementation of Maritime Spatial Planning in the Russian Federation and Ways to Overcome Them. In Proceedings of the Materials of XXI International Environmental Forum “Baltic Sea Day". 2021. Available online: http://helcom.ru/baltic_sea_day/2021_year/BSD2021_ materials_ENG (accessed on 8 July 2021).

37. Semeoshenkova, V.S.; Plink, N.L.; Eremina, T.R.; Ershova, A.A. Recommendations for solving the problems of the implementation of maritime spatial planning in the Russian Federation. "Modern problems of hydrometeorology and environmental monitoring in the CIS". In Proceedings of the International Scientific and Practical Conference dedicated to the 90th anniversary of the Russian State Hydrometeorological University, St. Petersburg, Russia, 22-24 October 2020; Russian State Hydrometeorological University: St. Petersburg, Russia, 2020; pp. 81-83.

38. Zaucha, J. Sea basin maritime spatial planning: A case study of the Baltic Sea region and Poland. Mar. Policy 2014, 50, 34-45. [CrossRef] 